\title{
Absorção de cálcio e magnésio por cultivares de aveia submetidas a níveis de toxidez por alumínio
}

\author{
Calcium and magnesium uptake by oat cultivars subjected to \\ aluminum toxicity levels
}

\author{
José Antonio Gonzalez da Silva ${ }^{1}$; Cecilia Estima Sacramento Reis ${ }^{2}$; \\ Maraisa Crestani ${ }^{3}$; Rogerio Oliveira de Sousa ${ }^{4}$; \\ Antonio Costa de Oliveira ${ }^{4 *}$; Fernando Irajá Félix de Carvalho ${ }^{5}$
}

\section{Resumo}

Solos ácidos com elevadas concentrações de alumínio (Al) afetam a produtividade em aveia e outras culturas. A toxicidade deste cátion, além de reduzir o crescimento das raízes, interfere na absorção, transporte e utilização de nutrientes como o magnésio $(\mathrm{Mg})$ e o cálcio $(\mathrm{Ca})$. O objetivo do trabalho foi avaliar a capacidade de absorção de $\mathrm{Ca}$ e $\mathrm{Mg}$ no tecido foliar de cultivares de aveia branca padrões de tolerância e sensibilidade ao Al, em condição hidropônica, e verificar se genótipos com maior capacidade de absorção destes elementos $(\mathrm{Ca}$ e $\mathrm{Mg})$ representam constituições genéticas tolerantes. No estudo, dois experimentos foram constituídos, um para validar os grupos de tolerância com base na retomada do crescimento de raiz e outro visando disponibilizar quantidade de matéria seca suficiente para as determinações de $\mathrm{Ca}$ e $\mathrm{Mg}$. Nas duas situações, o delineamento experimental foi o completamente casualizado num fatorial $3 \times 6$ para dose de $\mathrm{Al}$ e genótipo com três repetições. A absorção de $\mathrm{Ca}$ e $\mathrm{Mg}$ são afetadas pela adição de $\mathrm{Al}$ na solução hidropônica, com cultivares do padrão tolerante, mostrando maior absorção no tecido foliar que as sensíveis na ausência do Al e sob condições mais restritivas do íon tóxico. Portanto, há uma ligação do nível de tolerância ao Al com a capacidade de absorção destes elementos, representando uma variável a ser empregada na seleção de genótipos mais eficientes.

Palavras-chave: Avena sativa L., hidroponia, tolerância, médias e regressão

\begin{abstract}
Acid soils with high aluminum (Al) concentrations affect the productivity of oats and many crops. The toxicity of this cation, besides reducing root growth, interferes on the uptake, transport and use of nutrients such as magnesium $(\mathrm{Mg})$ and calcium $(\mathrm{Ca})$. The objective of this work was to evaluate the $\mathrm{Ca}$ and $\mathrm{Mg}$ uptake ability by measuring their content in the leaf tissues of white oat cultivars. Tolerant and sensitive cultivars were tested under hydroponic culture to verify if the genotypes with greater uptake ability of $\mathrm{Ca}$ and $\mathrm{Mg}$ do represent those with a tolerant response. In the study, two experiments were performed, one to validate the tolerance groups based on root regrowth and another aiming to reach plant dry masses large enough to determine $\mathrm{Ca}$ and $\mathrm{Mg}$. In both situations, the experimental design was completely random at a $3 \times 6$ factorial for dose and genotype with three replications. The uptake of $\mathrm{Ca}$ and $\mathrm{Mg}$ are affected by the addition of $\mathrm{Al}$ to the hydroponic solution, with tolerant cultivars

\footnotetext{
1 Prof. da Universidade Regional do Noroeste do Estado do Rio Grande do Sul, UNIJUÍ, Ijuí. E-mail:jagsfaem@yahoo.com.br

2 Discente do Programa de Pós-Graduação em Agronomia, Universidade Federal de Pelotas, UFPel, Pelotas, RS. E-mail: cecilia quimica@yahoo.com.br

3 Discente do Programa de Pós-Graduação em Agronomia, UFPel, Pelotas, RS. E-mail: maraisacrestani@gmail.com

4 Profs. Associados, UFPel, Pelotas, RS. E-mail: rogeriosousa@ufpel.edu.br; acostol@cgfufpel.org

5 Prof. Aposentado, UFPel, Pelotas, RS. E-mail:carvalho@ufpel.edu.br

Autor para correspondência
} 
showing higher concentrations on the leaf tissues than sensitive ones in the absence and presence of Al. Therefore, there is a link between the tolerance levels with the Al uptake, representing a variable to be employed on the selection of more efficient genotypes.

Key words: Avena sativa L., hydroponics, tolerance, means and regression

\section{Introdução}

Reduzidos valores de $\mathrm{pH}$ combinados com elevadas concentrações de alumínio (Al) são uma das principais causas da redução da produtividade na aveia branca, bem como, de outras culturas. A acidificação do solo pode afetar o crescimento das raízes e a absorção de nutrientes essenciais e permitir a liberação de $\mathrm{Al}$ ao meio (FERREIRA; MOREIRA; RASSINI, 2006), que em níveis tóxicos, pode levar à redução do crescimento e à alteração na absorção de íons pelos vegetais. Ressalta-se que é difícil observar os danos causados pelo $\mathrm{Al}$ ou $\mathrm{pH}$ separadamente (BASSO et al., 2003). Além disto, a avaliação da tolerância ao $\mathrm{Al}$ em condições de campo e o tipo de caráter em avaliação pode tornar sua eficiência diminuída pela influência de vários fatores de difícil controle e mensuração que atuam sobre o desempenho das plantas, induzindo ao erro (FERREIRA; MOREIRA; RASSINI, 2006). Por isso, o cultivo hidropônico vem sendo empregado na seleção de plantas tolerantes ao $\mathrm{Al}$, pois, facilita os trabalhos pelo maior controle experimental, facilidade de visualização do efeito específico deste íon sobre o caráter, precocidade de avaliação em nível de plântula e representa método não destrutivo e com elevada correlação com resultados obtidos em condições de campo (CAMARGO; OLIVEIRA, 1981; SPEHAR; SOUZA, 2006).

$\mathrm{O}$ Al é um íon metálico que interfere na absorção, transporte e uso de elementos como $\mathrm{Mg}$ (KOCHIAN, 1995; FREITAS et al., 2006) e o Ca (SALVADOR; MOREIRA; MALAVOLTA, 2000; FREITAS et al., 2006), comprometendo a adequada nutrição e aquisição e transporte de água pelas plantas. Faquin e Vale (1991) comentam que o Al na forma solúvel, compete com o Ca e o $\mathrm{Mg}$ pelos mesmos sítios de absorção no complexo de troca das raízes. Além do que, a absorção de $\mathrm{Ca}$ e $\mathrm{Mg}$ são progressivamente reduzidas com o aumento da concentração de Al na solução, afetando o transporte desses elementos para a parte aérea das plantas (SALVADOR; MOREIRA; MALAVOLTA, 2000; CRESTANI et al., 2009).

$\mathrm{O} \mathrm{Ca}$ é um elemento químico envolvido em processos que vão desde a síntese de paredes celulares e da lamela média que separa as células em divisão. É o mensageiro secundário em várias respostas das plantas aos sinais de ambiente e hormonal, ligandose a calmodulina, proteína do citosol responsável pela regulação de muitos processos metabólicos. O $\mathrm{Mg}$ desempenha um papel específico na ativação de enzimas envolvidas na respiração, no processo de fotossíntese e da síntese de DNA e RNA nas células vegetais (SANDERS; BROWNLEE; HARPER, 1999; TAIZ; ZEIGER, 2004; FREITAS et al., 2006). Portanto, solos com teores elevados de Al e cultivares sensíveis podem determinar a deficiência de $\mathrm{Ca}$ e $\mathrm{Mg}$ no tecido. Os sintomas de deficiência de Ca vão do surgimento de necrose nas regiões meristemáticas jovens, redução da divisão celular e formação de clorose e curvamento das folhas. $\mathrm{O} \mathrm{Mg}$, por fazer parte da molécula de clorofila, sua deficiência também acarreta na redução da eficiência fotossintética, com sintomas na forma de clorose entre as nervuras foliares chegando-se até a coloração branca no tecido foliar (FOY, 1984; TAIZ; ZEIGER, 2004; CRESTANI et al., 2009).

O uso de cultivares de aveia branca tolerantes ao Al representa uma solução sustentável e com ganhos permanentes em solos com presença deste íon tóxico, vinculado ao efeito cumulativo no desempenho de produção em solos com $\mathrm{pH}$ corrigidos (SILVA et al., 2007). Neste sentido, a utilização de técnicas mais eficientes de seleção de plantas tolerantes como o cultivo hidropônico aliado a análise da capacidade de absorção de Ca e Mg pela aveia sob condição de 
estresse, podem permitir ganhos mais significativos na identificação de genótipos eficientes na utilização destes nutrientes em solos com presença de Al. Neste contexto, o trabalho tem como objetivo avaliar a capacidade de absorção de $\mathrm{Ca}$ e $\mathrm{Mg}$ no tecido foliar de cultivares de aveia branca padrões de tolerância e sensibilidade ao Al sob condição hidropônica e verificar se genótipos com maior capacidade de absorção destes elementos ( $\mathrm{Ca}$ e $\mathrm{Mg}$ ) representam constituições genéticas tolerantes, validando a utilização destas variáveis na identificação de plantas mais eficientes.

\section{Material e Métodos}

Os estudos foram conduzidos no Laboratório de Duplo-haplóides e Hidroponia do Centro de Genômica e Fitomelhoramento do Departamento de Fitotecnia e no Laboratório de Nutrição de Plantas e Química do Solo do Departamento de Solos da Faculdade de Agronomia Eliseu Maciel/ Universidade Federal de Pelotas. Foram testadas seis cultivares de aveia branca recomendadas para cultivo no sul do Brasil, representando genótipos padrões quanto a tolerância e sensibilidade ao Al, de acordo com trabalhos já descritos na literatura: ALBASUL, UFRGS 15 e URS22 = sensíveis e; UPFA 22, URS 20 e UPF $19=$ tolerantes (FINATTO et al., 2007; REIS et al., 2009).

O primeiro experimento consistiu em analisar as seis cultivares padrões em três doses de alumínio (0, 7 e $\left.21 \mathrm{mg} \mathrm{L}^{-1}\right)$, para confirmação do nível de tolerância, como relatado na literatura, empregando como indicador a variável retomada do crescimento de raiz (RCR), como sugere Silva et al. (2007). $\mathrm{O}$ delineamento experimental utilizado foi $\mathrm{o}$ completamente casualizado num fatorial $3 \times 6$ para dose egenótipo, respectivamente, com três repetições e 12 plântulas de cada genótipo para representar a média de cada repetição. Foi efetuado o descasque e desinfestação das sementes com hipoclorito de sódio ( $20 \%$ do produto comercial e $80 \%$ de água destilada) por um minuto e três lavagens com água destilada para remoção do produto desinfestante. A seguir, as sementes foram colocadas em gerbox, sobre faixas de papel filtro umedecido e levadas à BOD (câmara de germinação) com temperatura de $20{ }^{\circ} \mathrm{C}$ e iluminação permanente por 48 horas para germinação. Após, as sementes germinadas foram transferidas para telas plásticas adaptadas às tampas de recipientes plásticos (baldes) com capacidade de 5,5 L, contendo solução nutritiva normal (sem Al) segundo protocolo desenvolvido por Camargo e Oliveira (1981) e $\mathrm{pH}$ regulado para 4,0 $\pm 0,3$. Os baldes, contendo solução nutritiva e as cultivares para avaliação, foram colocados em tanque de hidroponia à temperatura de $22{ }^{\circ} \mathrm{C}$, iluminação artificial permanente e sistema de aeração adicionado individualmente às soluções para dotação adequada de oxigênio às raízes. As plântulas foram mantidas por $48 \mathrm{~h}$ em solução sem alumínio. Após, as telas com as plântulas foram transferidas para novos baldes de 5,5 L com solução nutritiva normal (10\%) e doses de 0,7 e $21 \mathrm{mg} . \mathrm{L}^{-1}$ de Al, permanecendo por mais $48 \mathrm{~h}$, em $\mathrm{pH}$ ajustado para $4,0 \pm 0,3$, de modo a evitar a precipitação de compostos insolúveis, principalmente hidróxido de alumínio. $\mathrm{Na}$ última etapa de execução deste experimento, as telas retornaram à solução nutritiva normal permanecendo por mais $72 \mathrm{~h}$ a fim de permitir a RCR, principalmente dos genótipos tolerantes. Para avaliação do efeito do $\mathrm{Al}$ nos genótipos testados, a RCR foi mensurada com o auxílio de uma régua, a partir do ponto de dano causado pelo Al na raiz principal, caracterizado por um escurecimento e engrossamento da raiz.

O segundo experimento foi conduzido em delineamento experimental completamente casualizado com três repetições, seguindo um arranjo fatorial do tipo $6 \times 3$ para genótipo (cultivares padrões tolerantes e sensíveis) e dose de Al adicionado em solução nutritiva ( 0,7 e $\left.21 \mathrm{mg} . \mathrm{L}^{-1}\right)$, consistindo de 54 unidades experimentais (baldes), com aproximadamente 200 plântulas por balde para disponibilizar quantidade de matéria seca suficiente para as determinações espectrofotométricas. 
Anterior à montagem do experimento, as sementes dos genótipos padrões foram descascadas e desinfestadas e levadas a BOD para germinação das sementes, conforme relatado para o primeiro experimento. A seguir, as sementes germinadas foram transferidas para telas plásticas adaptadas às tampas de recipientes plásticos (baldes) com capacidade de 5,5 L, contendo a solução nutritiva normal (sem Al), mesmo protocolo desenvolvido por Camargo e Oliveira (1981) com pH de 4,0 \pm 0,3. Portanto, a solução foi obtida pela diluição em 5,5 $\mathrm{L}$ de água destilada com: $65 \mathrm{~mL}$ de $\mathrm{Ca}\left(\mathrm{NO}_{3}\right)_{2} \cdot 4 \mathrm{H}_{2} \mathrm{O}$ 78,4 g. L L $1,65 \mathrm{~mL}$ de $\mathrm{MgSO}_{4} \cdot 7 \mathrm{H}_{2} \mathrm{O}$ 40,92 g. $\mathrm{L}^{-1}, 65$ $\mathrm{mL}$ de $\mathrm{KNO}_{3} 33,57$ g. $\mathrm{L}^{-1}, 65 \mathrm{~mL}$ de $\left(\mathrm{NH}_{4}\right)_{2} \mathrm{SO}_{4} 4,77$ g.L $\mathrm{L}^{-1}, 65 \mathrm{~mL} \mathrm{KH} \mathrm{PO}_{4} 65$ g.L $\mathrm{L}^{-1}, 6,5 \mathrm{~mL}$ de Fe-EDTA 43,25 g.L $\mathrm{L}^{-1}$ e $65 \mathrm{~mL}$ da solução de micronutrientes que é formada pela adição de: $10 \mathrm{~mL}$ de $\mathrm{H}_{3} \mathrm{BO}_{3}$ 0,05146 g.L $\mathrm{L}^{-1}, 1 \mathrm{~mL}$ de $\mathrm{Na}_{2} \mathrm{MoO}_{4} \cdot 2 \mathrm{H}_{2} \mathrm{O} 0,00201$ g. $\mathrm{L}^{-1}, 10 \mathrm{~mL}$ de $\mathrm{NaCl} 0,14567 \mathrm{~g} . \mathrm{L}^{-1}, 1 \mathrm{~mL}$ de $\mathrm{ZnSO}_{4} .7 \mathrm{H}_{2} \mathrm{O} 0,01906$ g. $\mathrm{L}^{-1}, 1 \mathrm{~mL}$ de $\mathrm{CuSO}_{4} \cdot 5 \mathrm{H}_{2} \mathrm{O}$ 0,00623 g.L $\mathrm{L}^{-1}$ e $1 \mathrm{~mL}$ de $\mathrm{MnSO}_{4} \cdot \mathrm{H}_{2} \mathrm{O} 0.03702$ g.L $\mathrm{L}^{-1} \mathrm{a}$ 2L de água destilada.

Os baldes com as plântulas foram colocados em tanque de hidroponia à temperatura de $25^{\circ} \mathrm{C}$, iluminação artificial permanente e sistema de aeração individualmente por balde para dotação de oxigênio às raízes. As plântulas foram mantidas por 48 horas em solução sem alumínio. Após, em cada tela contendo as plântulas, foram transferidas para novos baldes de 5,5 L com solução nutritiva normal $(10 \%)$ e doses de 0,7 e 21 mg.L $L^{-1}$ de alumínio, permanecendo nesta condição por 48 horas. Seguindo, as telas retornaram à solução nutritiva normal permanecendo por mais 72 horas a fim de favorecer o desenvolvimento das plântulas. Foi realizada a coleta da parte aérea e submetidas a estufa de circulação de ar forçada a $65^{\circ} \mathrm{C}$ por 72 horas para secagem, seguida da trituração da matéria seca para a realização da digestão das amostras. Foi efetuada a determinação quantitativa de $\mathrm{Ca}$ e $\mathrm{Mg}$ por espectrofotometria de absorção atômica segundo metodologia descrita por Tedesco et al. (1995).
Os dados referentes ao desempenho dos genótipos padrões de tolerância ao $\mathrm{Al}$ para a RCR foram direcionados ao teste de hipótesee de médias por Scott \& Knott. E, na absorção de Ca e Mg no tecido foliar, os resultados foram submetidos à análise de variância, teste de médias por Scott \& Knott e ajuste de equação de regressão e grau do polinômio com interpolação do ponto $14 \mathrm{mg} \mathrm{L}^{-1} \mathrm{de}$ Al para integralizar a interpretação dos resultados. Todos os procedimentos foram realizados com o auxílio dos programas computacionais Genes (CRUZ, 2001) e SAS (2002).

\section{Resultados e Discussão}

Os resultados da análise de variância (não apresentados) mostraram que as diferenças entre os genótipos avaliados, as doses de alumínio aplicadas, bem como a interação genótipo $\mathrm{x}$ dose foram confirmadas pelo teste $\mathrm{F}$ para as variáveis $\mathrm{RCR}$ e absorção de $\mathrm{Ca}$ e $\mathrm{Mg}$ no tecido foliar. A análise prosseguiu pelo desdobramento destas interações em seus efeitos simples nos testes de comparação de médias apresentadas nas tabelas 1 e 2 . Na tabela 1 , fato relevante está na análise do comportamento dos genótipos em cada concentração do elemento tóxico, indicando que os padrões tolerantes na ausência de Al mostram diferenças genéticas distintas e superiores aquelas do grupo sensível quanto ao comprimento da raiz. Outro ponto é a superioridade apresentada do grupo tolerante nas demais doses do elemento químico estudado (7 e $21 \mathrm{mg} \mathrm{L}^{-1}$ ), efetivamente confirmando maior RCR independente destas concentrações. Aliado a isto, as diferenças entre os pontos de 7 e $21 \mathrm{mg} \mathrm{L}^{-1}$ de $\mathrm{Al}$ apenas ocorreu nas cultivares tolerantes, mostrando que, nas sensíveis, a dose de $7 \mathrm{mg} \mathrm{L}^{-1}$ foi suficiente em reduzir fortemente a RCR a tal ponto de estabilizar sua expressão, confirmando os resultados obtidos em estudos anteriores (FINATTO et al., 2007; SILVA et al., 2007). O RCR é uma variável eficiente na determinação do nível de tolerância ao $\mathrm{Al}$, pois o íon tóxico se faz presente predominantemente na 
região radicular da planta, com os ápices radiculares representando seu sítio crítico de toxicidade (RYAN; DITOMASO; KOCHIAN, 1993). Para Machado (1997), quando este cátion é absorvido ocorre a paralisação da divisão celular no meristema apical das raízes, resultando em drástica redução de seu crescimento, que a partir de uma condição favorável na ausência do íon tóxico, novamente inicia a capacidade de divisão celular favorecendo a retomada do crescimento da raiz (RCR), principalmente dos genótipos tolerantes.

Tabela 1. Valor médio da retomada de crescimento da raiz (RCR), em centímetros, para as dezenove cultivares avaliadas em concentrações de 0,7 e $21 \mathrm{mg} . \mathrm{L}^{-1}$ de $\mathrm{Al}^{3+}$ na solução. FAEM/UFPel/2011.

\begin{tabular}{|c|c|c|c|c|}
\hline \multirow{2}{*}{ Genótipo } & \multirow{2}{*}{ Genealogia } & \multicolumn{3}{|c|}{ Dose de Al (RCR) } \\
\hline & & $0 \mathrm{mg} \mathrm{L}^{-1}$ & $7 \mathrm{mg} \mathrm{L}^{-1}$ & $21 \mathrm{mg} \mathrm{L}^{-1}$ \\
\hline URS $20(T)$ & UFRGS $86^{\mathrm{A}} 1194-2$ / UFRGS 8 & $4,81 \mathrm{a}$ & A 2,04 a & B $0,60 \mathrm{a}$ \\
\hline UPF 19 (T) & $\begin{array}{c}90 \mathrm{SA}-30(\mathrm{UPF} 16) / 90 \mathrm{AS}-28 \\
(\mathrm{Cor} 2 * / \mathrm{Ctz} 3 * / \text { Pendek/ME1563) }\end{array}$ & $4,08 \mathrm{a}$ & A $1,44 \mathrm{a}$ & B $0,84 \mathrm{a}$ \\
\hline UPFA $22(\mathrm{~T})$ & $\begin{array}{c}\text { 90SAP-37 (UFRGS 10)/90SAP-28 (Cor2*/Ctz3*/ } \\
\text { Pendek/ME1563) }\end{array}$ & $5,07 \mathrm{a}$ & A 1,87 a & B 0,79 a \\
\hline ALBASUL (S) & UFRGS 14 / UFRGS 881920 & $2,45 \mathrm{~b}$ & A $0,25 \mathrm{~b}$ & $\mathrm{~A} 0,23 \mathrm{~b}$ \\
\hline UFRGS 15 (S) & $\begin{array}{c}\text { Cor2*/Ctz3*/Pendek/ME1563/ } \\
\text { C16CRcpx/C7512/SRcpx74C8014 }\end{array}$ & $3,33 \mathrm{~b}$ & A $0,63 \mathrm{~b}$ & A 0,28 b \\
\hline URS $22(\mathrm{~S})$ & UFRGS 884110 / UFRGS $884021-1$ & $3,34 \mathrm{~b}$ & A 0,66 b & A $0,27 \mathrm{~b}$ \\
\hline
\end{tabular}

Médias não abrangidas pela mesma letra minúscula, na coluna ou pela mesma letra maiúscula, na linha, diferiram estatisticamente a 5\% de probabilidade de erro pelo teste de Scott Knott. Os sinais / e // indicam a ordem em que os cruzamentos foram realizados; os retrocruzamentos estão simbolizados com um asterisco $\left(^{*}\right)$ e o número indica o número de retrocruzamentos com o genitor recorrente.

Fonte: Elaboração dos autores.

As variáveis teores de $\mathrm{Ca}$ e $\mathrm{Mg}$, foi verificado que na dose padrão (sem $\mathrm{Al}$ ), as cultivares estudadas evidenciaram comportamento distinto, indicando, uma capacidade particular de cada genótipo na absorção desses íons bivalentes. Outro aspecto, está no maior acúmulo de Ca pelos genótipos URS 20 "a" e UPF 19, caracterizados como tolerantes e os menores valores de absorção para a UFRGS 15 “d” e URS 22 do grupo sensível. No entanto, tanto a cultivar UPF 19 (tolerante) como a ALBASUL (sensível) apresentaram o mesmo comportamento. $\mathrm{Na}$ análise da absorção do $\mathrm{Mg}$ no tecido foliar (Tabela 2), com ausência de Al, os resultados foram ainda mais expressivos, com os genótipos do grupo tolerante superiores ao sensível sem sobreposição de classes, configurando também, uma possível ligação entre os genes de tolerância ao $\mathrm{Al}$ e a capacidade de absorção de $\mathrm{Mg}$ às folhas. Cabe mencionar nesta condição, a capacidade de absorção de $\mathrm{Mg}$ pelos genótipos URS 20 e UPFA 22 "a" seguido da UPF 19 "b", ao contrário da ALBASUL "c", URS 22 "d" e UFRGS 15 "e", com os menores desempenhos. Na média geral, com ausência de $\mathrm{Al}$, os grupos testados diferiram significativamente entre si tanto para a capacidade de absorção de $\mathrm{Ca}$ (Tolerantes =3,83 $\mathrm{g} \mathrm{kg}^{-1}$ " a+" versus Sensível=2,39 $\mathrm{g} \mathrm{kg}^{-1}$ "b+") como de $\mathrm{Mg}$ (Tolerantes=2,85 g $\mathrm{kg}^{-1}$ "a+" versus Sensível=2,14 g Kg-1 “b+"), ratificando as observações constatadas. Freitas et al. (2006) estudando o efeito do Al na absorção de macronutrientes em arroz mostraram que genótipos mais eficientes em suportar o estresse do ín metálico foram os que evidenciaram no tecido foliar maiores teores de $\mathrm{Ca}$, sugerindo que este elemento representa uma característica fisiológica importante na observação do nível de tolerância desta espécie. 
Este fato reforça a hipótese levantadas por Jones et al. (1998) de que a toxidez por Al em plantas esteja ligada ao bloqueio de Canais de Ca na membrana plasmática e que o Mg quando em competição com o Al pode desativar enzimas envolvidas na respiração e fotossíntese, afetando o tecido na mesma proporção (SANDERS; BROWNLEE; HARPER, 1999). Portanto, genótipos de aveia que evidenciam eficiência fisiológica na absorção de $\mathrm{Ca}$ e $\mathrm{Mg}$ no tecido também podem representar genótipos mais eficientes na recomendação de cultivo em áreas marginais ou de elevada acidez e Al no solo.

Tabela 2. Valores médios da absorção de cálcio e magnésio $\left(\mathrm{g} \mathrm{kg}^{-1}\right)$ no tecido foliar de genótipos de aveia branca padrões de tolerância ao Al sob concentrações de 0,7 e $21 \mathrm{mg} \mathrm{L}^{-1}$ do íon metálico na solução. FAEM/UFPel/2011.

\begin{tabular}{|c|c|c|c|c|}
\hline \multirow{2}{*}{ Grupo } & \multirow{2}{*}{ Genótipos } & \multicolumn{3}{|c|}{ Cálcio $\left(\mathrm{g} \mathrm{kg}^{-1}\right)$ em doses de $\mathrm{Al}\left(\mathrm{mg} \mathrm{L}^{-1}\right)$} \\
\hline & & 0 & 7 & 21 \\
\hline \multirow{3}{*}{$\mathrm{T}$} & URS 20 & A 4,93 a & B $2,52 \mathrm{c}$ & A 4,51 a \\
\hline & UPF 19 & A $3,00 \mathrm{c}$ & $\mathrm{C} 1,58 \mathrm{e}$ & B $2,45 \mathrm{c}$ \\
\hline & UPFA 22 & A $3,57 \mathrm{~b}$ & B $2,79 \mathrm{~b}$ & A $3,54 \mathrm{~b}$ \\
\hline Média & & $\mathrm{A}^{+} 3,83 \mathrm{a}^{+}$ & $\mathrm{B}^{+} 2,30 \mathrm{a}^{+}$ & $\mathrm{A}^{+} 3,50 \mathrm{a}^{+}$ \\
\hline \multirow{3}{*}{$\mathrm{S}$} & ALBASUL & A 2,92 c & A 3,11 a & B $1,10 \mathrm{e}$ \\
\hline & UFRGS 15 & A $2,30 \mathrm{~d}$ & B $1,98 \mathrm{~d}$ & B $2,02 \mathrm{~d}$ \\
\hline & URS 22 & B $1,97 \mathrm{~d}$ & A $2,43 \mathrm{c}$ & B $1,84 \mathrm{~d}$ \\
\hline Média & & $\mathrm{A}^{+} 2,39 \mathrm{~b}^{+}$ & $\mathrm{A}^{+} 2,50 \mathrm{a}^{+}$ & $\mathrm{B}^{+} 1,65 \mathrm{~b}^{+}$ \\
\hline \multirow{2}{*}{ Grupo } & \multirow{2}{*}{ Genótipos } & \multicolumn{3}{|c|}{ Magnésio $\left(\mathrm{g} \mathrm{kg}^{-1}\right)$ em doses de $\mathrm{Al}\left(\mathrm{mg} \mathrm{L}^{-1}\right)$} \\
\hline & & 0 & 7 & 21 \\
\hline \multirow{3}{*}{$\mathrm{T}$} & URS 20 & A 2,96 a & B 2,20 a & A 3,07 a \\
\hline & UPF 19 & A $2,52 \mathrm{~b}$ & B $2,07 \mathrm{~b}$ & A $2,52 \mathrm{~b}$ \\
\hline & UPFA 22 & A 3,09 a & $\mathrm{C} 1,97 \mathrm{c}$ & B $2,63 \mathrm{~b}$ \\
\hline Média & & $\mathrm{A}^{+} 2,85 \mathrm{a}^{+}$ & $\mathrm{B}^{+} 2,08 \mathrm{a}^{+}$ & $\mathrm{A}^{+} 2,74 \mathrm{a}^{+}$ \\
\hline \multirow{3}{*}{$\mathrm{S}$} & ALBASUL & A $2,28 \mathrm{c}$ & A $2,26 \mathrm{a}$ & B $1,92 \mathrm{c}$ \\
\hline & UFRGS 15 & A $1,95 \mathrm{e}$ & A $2,05 \mathrm{~b}$ & B $1,88 \mathrm{c}$ \\
\hline & URS 22 & A $2,19 \mathrm{~d}$ & B $1,98 \mathrm{c}$ & $\mathrm{C} 1,77 \mathrm{c}$ \\
\hline Média & & $\mathrm{A}^{+} 2,14 \mathrm{~b}^{+}$ & $\mathrm{A}^{+} 2,10 \mathrm{a}^{+}$ & $\mathrm{B}^{+} 1,85 \mathrm{~b}^{+}$ \\
\hline
\end{tabular}

Médias seguidas pela mesma letra minúscula na coluna e maiúscula na linha não diferiram estatisticamente entre si. Médias com a mesma letra minúscula na coluna com sinal + não diferem estatisticamente entre os grupos (tolerante e sensível) e; mesma letra maiúscula na linha com sinal + não diferem na média geral do grupo entre as doses testadas de Al. Todos considerando 5\% de probabilidade de erro pelo teste de Scott \& Knott.

Fonte: Elaboração dos autores.

Na dose de $7 \mathrm{mg} . \mathrm{L}^{-1}$ de $\mathrm{Al}$ em solução, tanto para $\mathrm{Ca}$ como $\mathrm{Mg}$, uma forte sobreposição de classes foi observada, não mostrando ligação entre a capacidade de absorção destes elementos com base no nível de tolerância dos grupos. Este fato é atribuido ao comportamento apresentado de genótipos como ALBASUL, do grupo sensível, que evidenciou maior capacidade de absorção de Ca às folhas "a" em comparação a UPF 19 "e" do grupo tolerante de menor desempenho médio. Além disto, tanto a URS 20 (tolerante) como a URS 22 (sensível) mostraram o mesmo comportamento nesta variável. Se ressalta nesta condição, resultados semelhantes também obtidos na absorção de $\mathrm{Mg}$ às folhas, com a URS 20 (tolerante) e ALBASUL (sensível) apresentando similaridade na absorção deste íon, "a", o mesmo verificado para as cultivares UPF 19 (tolerante) e UFRGS 15 (sensível) classe "b" e UPFA 22 (tolerante) e URS 22 (sensível) de classe "c". Na análise média geral entre os grupos nesta concentração (Tabela 2), diferenças nao foram encontradas na absorção de $\mathrm{Ca}$ (Tolerantes $=2,30 \mathrm{~g}$ 
$\mathrm{kg}^{-1}$ “a+" versus Sensível=2,50 g kg-1 “a+") e $\mathrm{Mg}$ (Tolerantes=2,08 $\mathrm{g} \mathrm{kg}^{-1}$ “a+" versus Sensível=2,10 $\mathrm{g} \mathrm{kg}^{-1}$ "a+") reforçando estas observações. Os resultados na dose de $7 \mathrm{mg} . \mathrm{L}^{-1}$ de $\mathrm{Al}$ em solução parece não interferir na capacidade de absorção de $\mathrm{Ca}$ e $\mathrm{Mg}$ às folhas a ponto de não diferenciar genótipos sensíveis e tolerantes selecionados com base na RCR, levantando a hipótese que para estas variáveis, a dose de $\mathrm{Al}$ não representa níveis adequados para avaliação. Na aveia branca, os níveis indicados de Al em solução para a discriminação de genótipos sensíveis e tolerantes para a RCR se encontram no intervalo de 7 a $21 \mathrm{mg} \mathrm{L}^{-1}$ deste íon metálico (SÁNCHEZ-CHACÓN et al., 2000; SILVA et al., 2007). Contudo, na comparação entre os pontos 0 e $7 \mathrm{mg} \mathrm{L}^{-1}$ de $\mathrm{Al}$, danos mais expressivos foram observados na absorção de $\mathrm{Ca}$ e $\mathrm{Mg}$ na média geral dos genótipos tolerantes $\left(\mathrm{Ca}, 0 \mathrm{mg} \mathrm{L}^{-1} \mathrm{de} \mathrm{Al}=\right.$ " $\mathrm{A}^{+}$"

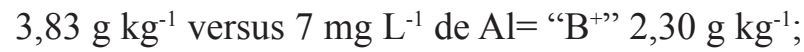
$\mathrm{Mg}, 0 \mathrm{mg} \mathrm{L}{ }^{-1} \mathrm{de} \mathrm{Al}=$ " $\mathrm{A}^{+}$" $2,85 \mathrm{~g} \mathrm{~kg}^{-1}$ versus $7 \mathrm{mg} \mathrm{L}{ }^{-1}$ de $\mathrm{Al}=$ " $\mathrm{B}^{+}$" 2,08 $\left.\mathrm{g} \mathrm{kg}^{-1}\right)$ em relação aos padrões de sensibilidade ( $\mathrm{Ca}, 0 \mathrm{mg} \mathrm{L}{ }^{-1}$ de $\mathrm{Al}=$ " $\mathrm{A}^{+}$" $2,39 \mathrm{~g} \mathrm{~kg}^{-1}$ versus $7 \mathrm{mg} \mathrm{L}^{-1} \mathrm{de} \mathrm{Al}=$ " $\mathrm{A}^{+}$" 2,50 $\mathrm{g} \mathrm{kg}^{-1} ; \mathrm{Mg}, 0 \mathrm{mg}$

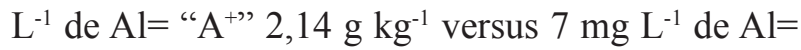
" $\mathrm{A}^{+}$" 2,10 $\mathrm{g} \mathrm{kg}^{-1}$ ), que não diferiram entre si (Tabela 2). Kochian (1995) e Freitas et al. (2006) relatam a existência de diferenças genotípicas nos sistema de transporte e absorção de $\mathrm{Ca}$ e $\mathrm{Mg}$ na presença de Al. Segundo estes mesmos autores, a observação do nível de tolerância principalmente dos genótipos tolerantes tem por base a concentração de Al que permita ativar os genes envolvidos em suportar o estresse do íon tóxico. Portanto, a dose empregada de $7 \mathrm{mg} \mathrm{L}^{-1}$ de $\mathrm{Al}$ parece nao estimular a expressão destes genes de tolerância na aveia branca sob condição hidropônica.

$\mathrm{Na}$ concentração de $21 \mathrm{mg} \cdot \mathrm{L}^{-1}$ de $\mathrm{Al}$, fato relevante foi que os genótipos tolerantes mostraram comportamento similar aquela sem adição do íon metálico em solução, com maior capacidade de absorção de $\mathrm{Ca}$ e $\mathrm{Mg}$ as folhas do que os padrões sensíveis, retomando nesta condição, a hipótese da ligação existente entre o nível de tolerância ao Al com a capacidade de absorção desses nutrientes. A cultivar URS 20 apresentou a maior absorçãode $\mathrm{Ca}$ no tecido "a", seguido da UPFA 22 "b" e UPF 19 "c", com os genótipos do grupo sensível de mais reduzidos valores (UFGRS 15 “d”, URS 22 “d” e ALBASUL “e”). Na absorção de $\mathrm{Mg}$, os genótipos tolerantes URS 20 "a”, UPF 19 "b" e UPFA 22 "b" mostraram os mais expressivos valores e as sensíveis UFGRS 15, URS 22 e ALBASUL, os menores desempenhos "c" (Tabela 2). Na média geral de comparação entre os grupos tolerante e sensível nesta dose mais elevada, diferenças foram confirmadas para a capacidade de absorção de $\mathrm{Ca}$ (Tolerantes $=3,50 \mathrm{~g} \mathrm{~kg}^{-1}$ "a+ " versus Sensível= 1,65 $\mathrm{g} \mathrm{kg}^{-1}$ "b+"), o mesmo acontecendo na absorção de $\mathrm{Mg}$ (Tolerantes= 2,74 $\mathrm{g} \mathrm{kg}^{-1}$ "a+" versus Sensível=1,85 $\mathrm{g} \mathrm{Kg}^{-1}$ " $\mathrm{b}+$ "). Desta forma, os resultados obtidos nesta condição, confirmam as observações relatadas anteriormente que, nos genótipos tolerantes, a eficiência é observada a partir de uma concentração (x) que permita ativar a expressão do gene ou genes de interesse. Em aveia branca a tolerância ao Al é controlada por um gene (OLIVEIRA, 2002; NAVA et al., 2006) ou por um ou dois genes dominantes (WAGNER; MILACH; FEDERIZZI, 2001). Os pesquisadores SánchezChacón et al. (2000), igualmente, concluíram que o controle genético da tolerância à toxicidade do Al nesta espécie e governada por um único gene com ação gênica de dominância. Contudo, em seu trabalho, é possível verificar a aditividade e a dominância parcial atuando na expressão deste caráter. Enquanto isto, quatro QTLs relacionados a tolerância ao $\mathrm{Al}$ foram descritos em aveia preta (Avena strigosa Schreb.), explicando 55\% da variação total da tolerância observada (WIGHT et al., 2006). Assim, a tolerância ao Al nesta espécie se caracteriza num caráter qualitativo, controlado por um pequeno número de genes de grande expressão no caráter, portanto, com maior facilidade de transferência de alelos de tolerância a genótipos elite sensíveis e de elevada eficiência de seleção em gerações segregantes precoces (ALLARD, 1960). 
Numa análise conjunta envolvendo os três pontos em observação $\left(0,7\right.$ e $\left.21 \mathrm{mg} \mathrm{L}^{-1}\right)$ percebe-se que os tolerantes mostraram na média concentrações de $\mathrm{Ca}$ e $\mathrm{Mg}$ reduzidas no ponto intermediário, no entanto, estatisticamente similar à dose padrão na concentração mais elevada de $\mathrm{Al},\left(\mathrm{Ca}, 0=\mathrm{A}^{+} 3,83 \mathrm{~g}\right.$ $\mathrm{kg}^{-1} ; 7=\mathrm{B}^{+} 2,30 \mathrm{~g} \mathrm{~kg}^{-1} ; 21 \mathrm{mg} \mathrm{L}^{-1}=\mathrm{A}^{+} 3,50 \mathrm{~g} \mathrm{~kg}^{-1} \mathrm{e}$ $\mathrm{Mg}, 0=\mathrm{A}^{+} 2,85 \mathrm{~g} \mathrm{~kg}^{-1} ; 7=\mathrm{B}^{+} 2,08 \mathrm{~g} \mathrm{~kg}^{-1} ; 21 \mathrm{mg} \mathrm{L}^{-1}=$ $2,74 \mathrm{~g} \mathrm{~kg}^{-1}$ ) o que parece indicar uma tendência quadrática na absorção deste dois elementos químicos. Por outro lado, no sensível, diferenças entre os pontos também foram constatados, de forma que, as médias apenas diferiram na dose mais elevada do ion tóxico $\left(\mathrm{Ca}, 0=\mathrm{A}^{+} 2,39 \mathrm{~g} \mathrm{~kg}^{-1} ; 7=\right.$ $\mathrm{A}^{+} 2,50 \mathrm{~g} \mathrm{~kg}^{-1} ; 21 \mathrm{mg} \mathrm{L}^{-1}=\mathrm{B}^{+} 1,65 \mathrm{~g} \mathrm{~kg}^{-1}$ e $\mathrm{Mg}, 0=$ $\mathrm{A}^{+} 2,14 \mathrm{~g} \mathrm{~kg}^{-1} ; 7=\mathrm{A}^{+} 2,10 \mathrm{~g} \mathrm{~kg}^{-1} ; 21 \mathrm{mg} \mathrm{L}^{-1}=\mathrm{B}^{+} 1,85$ $\mathrm{g} \mathrm{kg}^{-1}$ ), indicando direcionar a um comportamento linear. $\mathrm{Na}$ análise com três pontos, no máximo, o ajuste de uma linear é viabilizada, visto que, dois graus de liberdade serão direcionados para compor o erro experimental. Portanto, a análise prosseguiu no sentido de definir equações lineares para interpolação do ponto $14 \mathrm{mg} \mathrm{L}^{-1}$ de $\mathrm{Al}$ na solução e, a partir dos quatro pontos, efetivamente definir a tendência linear ou quadrática no comportamento dos genótipos com a significância dos parâmetros que definem estas equações.

$\mathrm{Na}$ tabela 3, a variável resposta absorção de $\mathrm{Ca}$ mostrou que os valores de quadrado médio (QM) dos genótipos tolerantes não evidenciaram significância no ajuste de equação linear, o que culminou com os reduzidos valores de coeficientes de determinação $\left(\mathrm{R}^{2}\right)$. Por outro lado, no grupo sensível, a significância na linearidade foi confirmada e, portanto, com valores de $\mathrm{R}^{2}$ mais elevados em comparação aos tolerantes. Já, na absorção de $\mathrm{Mg}$, este comportamento também foi observado, onde os genótipos tolerantes nao mostraram tendência linear nos pontos de $\mathrm{Al}$ testados $\left(0,7\right.$ e $\left.21 \mathrm{mg} \mathrm{L}^{-1}\right)$, ao contrário daqueles indicados como sensíveis. Cabe ressaltar que independente da presença e ausência de linearidade, a equação apresentada foi empregada para servir de base para estimativa da variável independente $(\mathrm{x})$ no ponto $14 \mathrm{mg} \mathrm{L}^{-1}$ de $\mathrm{Al}$, com valor da variável resposta (y) em \pm 1 Desvio Padrão (DP) pela sua interpolação $\left[\mathrm{y}=\mathrm{a}+\mathrm{b}_{14}( \pm 1 \mathrm{DP})\right]$, conforme tabela 3 . Assim, neste ponto de observação a absorção de $\mathrm{Ca}$ dos genótipos do grupo tolerante (URS $20=3,99$; UPF $19=2,27$ e UPFA $22=3,32 \mathrm{~g} \mathrm{~kg}^{-1}$ ) apresentaram valores mais elevados em comparação ao grupo de sensibilidade (Albasul= 1,93; UFRGS 15= 2,04; URS22 $\left.=2,03 \mathrm{~g} \mathrm{~kg}^{-1}\right)$. Além disto, a interpolação na absorção de $\mathrm{Mg}$ também indentificou valores superiores dos tolerantes (URS 20=2,81; UPF 19= 2,26; UPFA $\left.22=2,50 \mathrm{~g} \mathrm{~kg}^{-1}\right)$ frente aos padrões sensíveis (Albasul $=2,07$; UFRGS 15= 1,93; URS22 $\left.=1,88 \mathrm{~g} \mathrm{~kg}^{-1}\right)$. Portanto, fica evidente que o ponto $14 \mathrm{mg} \mathrm{L}^{-1}$ de $\mathrm{Al}$ em solução também mostra uma ligação com o nível de tolerância dos grupos formados, sugerindo que pode ser empregada na caracterização de genótipos quanto a absorção de $\mathrm{Ca}$ e $\mathrm{Mg}$ nas folhas, diferentemente do observado na concentração mais reduzida $\left(7 \mathrm{mg} \mathrm{L}^{-1}\right.$ de $\left.\mathrm{Al}\right)$. Cabe ressaltar que Crestani et al. (2011) ressaltam que as doses ideais que permitem caracterizar genótipos quanto a tolerância e sensibilidade ao Al são dependentes da espécie a ser estudada, do caráter em avaliação, da metodologia proposta e do tempo de exposição do órgão da planta em contato com o elemento tóxico. 
Tabela 3. Resumo da análise de variância de regressão, estimativa dos parâmetros de equação linear e interpolação do ponto $14 \mathrm{mg} \mathrm{L}^{-1}$ de $\mathrm{Al}$ na solução nas variáveis absorção de Ca e $\mathrm{Mg}$ no tecido foliar de genótipos de aveia branca padrões de tolerância sob concentrações de 0,7 e $21 \mathrm{mg} \mathrm{L}^{-1}$ do íon tóxico. FAEM/UFPel/2011.

\begin{tabular}{cccccc}
\hline GRUPO & Genótipo & $\mathrm{QM}_{\text {CÁLCIO }}$ & $\mathrm{R}^{2}$ & $\begin{array}{c}\text { Estimativa } \\
\left(\mathrm{y}=\mathrm{a}+\mathrm{b}_{\mathrm{x}}\right)\end{array}$ & $\begin{array}{c}\text { Interpolação } \\
\mathrm{y}=\mathrm{a}+\mathrm{b}_{14}( \pm 1 \mathrm{DP})\end{array}$ \\
\hline \multirow{2}{*}{$\mathrm{T}$} & URS 20 & $0,01^{\text {ns }}$ & 0,30 & $3,95+0,003_{\mathrm{x}}$ & $3,99( \pm 0,35)$ \\
& UPF 19 & $0,11^{\text {ns }}$ & 0,42 & $2,45-0,013_{\mathrm{x}}$ & $2,27( \pm 0,15)$ \\
& UPFA 22 & $0,03^{\text {ns }}$ & 0,31 & $3,24+0,006_{\mathrm{x}}$ & $3,32( \pm 0,14)$ \\
\hline \multirow{2}{*}{$\mathrm{S}$} & ALBASUL & $6,20^{*}$ & 0,73 & $3,26-0,095_{\mathrm{x}}$ & $1,93( \pm 0,10)$ \\
& UFRGS 15 & $0,18^{*}$ & 0,67 & $2,20-0,154_{\mathrm{x}}$ & $2,04( \pm 0,08)$ \\
& URS 22 & $0,19^{*}$ & 0,69 & $2,18-0,011_{\mathrm{x}}$ & $2,03( \pm 0,08)$ \\
\hline \multirow{2}{*}{ GRUPO } & Genótipo & $\mathrm{QM}_{\text {MAGNÉSIO }}$ & $\mathrm{R}^{2}$ & Estimativa & Interpolação \\
& URS 20 & $0,03^{\text {ns }}$ & 0,33 & $2,61+0,014_{\mathrm{x}}$ & $2,81( \pm 0,06)$ \\
& UPF 19 & $0,01^{\text {ns }}$ & 0,38 & $2,32-0,004_{\mathrm{x}}$ & $2,26( \pm 0,07)$ \\
\multirow{2}{*}{$\mathrm{T}$} & UPFA 22 & $0,04^{\text {ns }}$ & 0,53 & $2,67-0,012_{\mathrm{x}}$ & $2,50( \pm 0,06)$ \\
\hline \multirow{2}{*}{$\mathrm{S}$} & ALBASUL & $0,22^{*}$ & 0,84 & $2,32-0,018_{\mathrm{x}}$ & $2,07( \pm 0,07)$ \\
& UFRGS 15 & $0,11^{*}$ & 0,73 & $1,99-0,004_{\mathrm{x}}$ & $1,93( \pm 0,01)$ \\
& URS 22 & $0,25^{*}$ & 0,80 & $2,15-0,019_{\mathrm{x}}$ & $1,88( \pm 0,07)$ \\
\hline
\end{tabular}

*Significativo a $5 \%$ de probabilidade de erro; $\mathrm{QM}=$ Quadrado médio em $\mathrm{g} \cdot \mathrm{kg}^{-1}$ de cálcio e de magnésio nos genótipos avaliados. Fonte: Elaboração dos autores.

$\mathrm{Na}$ tabela 4, pela análise de regressão envolvendo os quatro pontos em observação $(0,7$, 14 e $21 \mathrm{mg} \mathrm{L}^{-1}$ de Al) o teste de significância para as equações do tipo linear e quadrática mostrou que na variável dependente absorção de $\mathrm{Ca}$ e $\mathrm{Mg}$, os genótipos tolerantes apresentaram tendência quadrática $\left(\mathrm{y}=\mathrm{a}+\mathrm{b}_{\mathrm{x}}+\mathrm{c}_{\mathrm{x}}{ }^{2}\right)$ no comportamento, a tal ponto de confirmar através de teste $t$ a significância do parâmetro $\left(\mathrm{c}_{\mathrm{x}}^{2}\right)$ no modelo. Desta forma, levando em consideração o desempenho individual de cada constituição genética nestas variáveis, a dose crítica (y), sendo $\mathrm{y}=-\mathrm{b} / 2 \mathrm{c}$, mostraram valores de $10,4 \mathrm{mg}$ $\mathrm{L}^{-1}$ (URS 20), 11,43 mg L-1 (UPF 19) e 10,2 $\mathrm{mg} \mathrm{L}^{-1}$ (UPFA 22) para absorção de Ca e 9,5 (URS 20), 9,1 mg L-1 (UPF 19) e 12,2 $\mathrm{mg} \mathrm{L}^{-1}$ (UPFA 22) no $\mathrm{Mg}$, confirmando os menores valores de translocação destes elementos as folhas nestas concentrações de Al na solução hidropônica. A partir daí, o incremento nos níveis do íon tóxico proporcionou em maior acúmulo do $\mathrm{Ca}$ e $\mathrm{Mg}$ no tecido, representando concentrações que definem o ponto de truncamento a partir do qual permite ativar genes de tolerância que estão intimamente ligados a capacidade de absorção de $\mathrm{Ca}$ e $\mathrm{Mg}$ no tecido foliar. Estudos realizados com milho por Ramírez e Berenjel (1984) demonstraram que linhagens tolerantes apresentam maior capacidade de translocar e acumular Al para a parte aérea da planta, onde linhagens sensíveis, pela reduzida capacidade de transporte acumulam maior quantidade no sistema radicular, aumentando conseqüentemente os danos à raiz. No entanto, a tolerância de várias espécies vegetais ao $\mathrm{Al}$ tem sido atribuída a maior capacidade de absorção nas raízes ou na parte aérea de certos macronutrientes essenciais (MALKANTHI et al., 1995). Em arroz, quase sempre cultivares tolerantes apresentam teores de $\mathrm{P}$, Ca e Mg mais elevados que as cultivares sensíveis (SIVAGURU; PALIWAL, 1993), onde a maior tolerância nesta espécie está relacionada à capacidade de absorção e eficiência na utilização destes nutrientes. 
Tabela 4. Resumo da análise de variância de regressão e estimativa dos parâmetros de equação linear e quadrática na absorção de $\mathrm{Ca}$ e $\mathrm{Mg}$ no tecido foliar de genótipos de aveia branca padrões de tolerância ao Al. FAEM/UFPel/2011.

\begin{tabular}{|c|c|c|c|c|c|c|}
\hline $\begin{array}{c}\text { Genótipo } \\
\text { (Ca) }\end{array}$ & $\begin{array}{l}\text { Fonte de } \\
\text { Variação }\end{array}$ & $\mathrm{QM}_{\mathrm{Ca}}$ & $\mathrm{R}^{2}$ & $\begin{array}{c}\text { Estimativa } \\
\left(\mathrm{y}=\mathrm{a}+\mathrm{b}_{\mathrm{x}}+\mathrm{c}_{\mathrm{x}}^{2}\right)\end{array}$ & $\begin{array}{l}\text { Parâmetros } \\
\left(b_{x}\right) \text { e }\left(c_{x}^{2}\right)\end{array}$ & $\begin{array}{c}(-\mathrm{b} / 2 \mathrm{c}) \\
\left(\mathrm{mg} \mathrm{L} \mathrm{L}^{-1}\right)\end{array}$ \\
\hline \multirow{2}{*}{$\begin{array}{c}\text { URS20 } \\
\text { (T) }\end{array}$} & $\mathrm{L}$ & $0,006^{\mathrm{ns}}$ & - & - & - & - \\
\hline & $\mathrm{Q}$ & $6,471^{*}$ & 0,82 & $4,69-0,311_{x}+0,015_{x}^{2}$ & $*$ & 10,4 \\
\hline \multirow{2}{*}{$\begin{array}{l}\text { UPF19 } \\
\text { (T) }\end{array}$} & $\mathrm{L}$ & $0,119^{\text {ns }}$ & - & - & - & - \\
\hline & Q & $1,904^{*}$ & 0,85 & $2,85-0,183_{\mathrm{x}}+0,008_{\mathrm{x}}^{2}$ & $*$ & 11,43 \\
\hline \multirow{2}{*}{$\begin{array}{l}\text { UPFA22 } \\
\text { (T) }\end{array}$} & $\mathrm{L}$ & $0,029^{\text {ns }}$ & - & - & - & - \\
\hline & Q & $0,760 *$ & 0,81 & $3,49-0,102 \mathrm{x}+0,005_{\mathrm{x}}^{2}$ & $*$ & 10,2 \\
\hline \multirow{2}{*}{$\begin{array}{l}\text { ALBASUL } \\
\text { (S) }\end{array}$} & $\mathrm{L}$ & $6,640^{*}$ & 0,93 & $3,26-0,095_{x}$ & $*$ & - \\
\hline & Q & $0,780^{\mathrm{ns}}$ & - & $-x^{2}$ & - & - \\
\hline \multirow{2}{*}{$\begin{array}{l}\text { UFRGS15 } \\
\text { (S) }\end{array}$} & $\mathrm{L}$ & $0,190^{*}$ & 0,82 & $2,20-0,011_{x}$ & $*$ & - \\
\hline & Q & $0,069^{\text {ns }}$ & - & - & - & - \\
\hline \multirow{2}{*}{ URS22 (S) } & $\mathrm{L}$ & $0,393^{*}$ & 0,86 & $2,18-0,011_{x}$ & $*$ & - \\
\hline & $\mathrm{Q}$ & $0,010^{\mathrm{ns}}$ & - & $-x^{x}$ & - & - \\
\hline $\begin{array}{l}\text { Genótipo } \\
\text { (Mg) }\end{array}$ & $\begin{array}{l}\text { Fonte de } \\
\text { Variação }\end{array}$ & $\mathrm{QM}_{\mathrm{Mg}}$ & $\mathrm{R}^{2}$ & $\begin{array}{c}\text { Estimativa } \\
\left(\mathrm{y}=\mathrm{a}+\mathrm{b}_{\mathrm{x}}+\mathrm{c}_{\mathrm{x}}{ }^{2}\right)\end{array}$ & & $\begin{array}{l}-b_{1} / 2 b_{2} \\
\left(m g L^{-1}\right)\end{array}$ \\
\hline \multirow{2}{*}{$\begin{array}{c}\text { URS20 } \\
\text { (T) }\end{array}$} & $\mathrm{L}$ & $0,137^{*}$ & 0,61 & $2,61+0,005_{x}$ & - & - \\
\hline & Q & $0,775^{*}$ & 0,87 & $2,87-0,095_{\mathrm{x}}+0,005_{\mathrm{x}}^{2}$ & * & 9,5 \\
\hline \multirow{2}{*}{$\mathrm{UPF} 19(\mathrm{~T})$} & $\mathrm{L}$ & $0,004^{\mathrm{ns}}$ & - & - & - & - \\
\hline & Q & $0,371^{*}$ & 0,89 & $2,49-0,073_{x}+0,004_{x}^{2}$ & $*$ & 9,1 \\
\hline \multirow{2}{*}{ UPFA22 (T) } & $\mathrm{L}$ & $0,110^{*}$ & 0,56 & $2,67-0,012_{x}$ & - & - \\
\hline & $\mathrm{Q}$ & $1,165^{*}$ & 0,79 & $2,98-0,146_{x}+0,006_{x}^{2}$ & $*$ & 12,2 \\
\hline \multirow{2}{*}{$\begin{array}{l}\text { ALBASUL } \\
\text { (S) }\end{array}$} & $\mathrm{L}$ & $0,240^{*}$ & 0,93 & $2,32-0,018_{x}$ & $*$ & - \\
\hline & Q & $0,012^{\text {ns }}$ & - & $-\quad x$ & - & - \\
\hline \multirow{2}{*}{$\begin{array}{l}\text { UFRGS15 } \\
\text { (S) }\end{array}$} & $\mathrm{L}$ & $0,014^{*}$ & 0,73 & $1,99-0,004_{x}$ & $*$ & - \\
\hline & Q & $0,005^{\text {ns }}$ & - & - & - & - \\
\hline \multirow{2}{*}{ URS22 (S) } & $\mathrm{L}$ & $0,276^{*}$ & 0,97 & $2,15-0,019 \mathrm{x}$ & $*$ & - \\
\hline & Q & $0,008^{\mathrm{ns}}$ & - & $-e^{x}$ & - & - \\
\hline
\end{tabular}

Fonte: Elaboração dos autores.

Analisando a tabela 4, é verificado que com o aumento gradativo das doses de $\mathrm{Al}$ na solução nutritiva ocorreu a redução na absorção de $\mathrm{Ca}$ e $\mathrm{Mg}$ às folhas nos genótipos do grupo de sensibilidade. No desempenho individual destes genótipos de acordo com a estimativa do modelo matemático apresentado pela regressão linear $\left(\mathrm{y}=\mathrm{a}+\mathrm{b}_{\mathrm{x}}\right)$ com significância no parâmetro $\left(b_{x}\right)$ da equação, foi constatado que a cada $1 \mathrm{mg} \mathrm{L}^{-1}$ de $\mathrm{Al}$ adicionado a solução reduz em 0,095 $\mathrm{g} \mathrm{kg}^{-1}$ (ALBASUL), 0,011 g $\mathrm{kg}^{-1}$ (UFRGS 15) e 0,011 $\mathrm{g} \mathrm{kg}^{-1}$ (URS 22) a absorção de Ca pelas folhas e $0,018 \mathrm{~g} \mathrm{~kg}^{-1}$ (ALBASUL), $0,004 \mathrm{~g} \mathrm{~kg}^{-1}$ (UFRGS15) e $0,019 \mathrm{~g} \mathrm{~kg}^{-1}$ (URS 22) a absorção de $\mathrm{Mg}$. Portanto, fica evidente que a sensibilidade ao Al observado nos genótipos testados refletiu na capacidade de absorção de 
$\mathrm{Ca}$ e $\mathrm{Mg}$ às folhas, ao contrário dos tolerantes, que apresentaram maior acúmulo destes cátions, mostrando a ligação existente da tolerância ao Al com a capacidade de absorção destes elementos as folhas e pode representar um parâmetro importante na identificação e seleção de genótipos de aveia branca tolerantes ao Al, principalmente quando a análise da RCR é dificultada ou não permite clara visualização (SILVA et al., 2007).

É importante mencionar que, de modo geral, os genitores que dão origem novas cultivares com tolerância ao $\mathrm{Al}$ tendem a ser oriundos de solos onde há elevada concentração deste íon metálico, já que, as sensíveis, geralmente são selecionadas em regiões com baixos níveis do elemento químico disponível. Bertan et al. (2005) estudando trigos originados da região sul do Brasil, observaram que os classificados como tolerantes eram provenientes de programas de melhoramento de áreas com elevada acidez, confirmando a hipótese de Andrade (1976), de que a tolerância ao Al pode estar intimamente ligada a origem de sua formação, pois, quando desenvolvido sem pressão de seleção, dificilmente terá em sua constituição genes efetivos para o caráter, reforçando a habilidade particular de aproveitamento de nutrientes como $\mathrm{Ca}$ e $\mathrm{Mg}$ dos genótipos que evidenciam genes de tolerância. Contudo, a forte difusão do sistema de semeadura direta no país, caracterizado pelo não revolvimento do solo fez com que a incorporação do calcário nas camadas mais profundas fosse prejudicada, já que, neste sistema, o calcário é aplicado apenas na superfície. Desta forma, o uso de variedades com maior capacidade de absorção de $\mathrm{Ca}$ e $\mathrm{Mg}$ representa uma forte alternativa à redução das necessidades de calcário, além da forte possibilidade de adaptação destas constituições genéticas a solos ácidos por estares relacionadas a um maior padrão de tolerância.

Hartwig et al. (2007) comentam que as pesquisas têm identificado constantemente genes que revelam relação com a tolerância ao $\mathrm{Al}$, abrindo novas fronteiras para as bases genéticas e moleculares da tolerância a esse elemento químico, como observado neste trabalho nas ligações que envolvem o nível de tolerância ao Al com a capacidade de absorção de $\mathrm{Ca}$ e $\mathrm{Mg}$ às folhas. Portanto, promover o emprego de novas técnicas na identificação de genótipos tolerantes ao Al como o uso de recursos fisiológicos e moleculares pode maximizar de sobremaneira o incremento de ganho genético na busca de genótipos superiores mais ajustados aos diferentes ambientes agrícolas.

\section{Conclusão}

A absorção de $\mathrm{Ca}$ e $\mathrm{Mg}$ são afetadas pela adição de Al na solução hidropônica, com cultivares do padrão tolerante mostrando maior absorção no tecido foliar que as sensíveis na ausência do Al e sob condições mais restritivas do íon tóxico. Portanto, há uma ligação do nível de tolerância ao Al com a capacidade de absorção destes elementos, representando uma variável a ser empregada na seleção de genótipos mais eficientes.

\section{Agradecimentos}

Os autores agradecem à Fundação de Amparo à Pesquisa do Estado do Rio Grande do Sul (FAPERGS) e ao Conselho Nacional de Desenvolvimento Científico e Tecnológico (CNPq) pelos auxílios recebidos em bolsas de graduação, pós-graduação e produtividade em pesquisa.

\section{Referências}

ALLARD, R. W. Principles of plant breeding. New York: John Wiley and Sons, 1960. 485 p.

ANDRADE, J. M. V. Seleção de genótipos de trigo (Triticum aestivum L.) tolerantes ao alumínio e ao manganês, com modificações das características químicas do solo. 1976. Dissertação (Mestrado em Agronomia - Fitotecnia) - Programa de Pós-graduação em Agronomia. Universidade Federal do Rio Grande do Sul, Porto Alegre. 
BASSO, L. H. M.; GONÇALVES, A. N.; SILVEIRA, L. V. A.; LIMA, G. P. P. Efeito do alumínio no crescimento de Eucalyptus grandis x E. urophylla cultivadas in vitro. Scientia Florestalis, Piracaba, v. 1, n. 63, p. 167-177, 2003.

BERTAN, I.; CARVALHO, F. I. F.; OLIVEIRA, A. C.; OLIVEIRA, P. H.; SILVA, J. A. G.; BENIN, G.; SILVA, G. O.; HARTWIG, I.; PADILHA, E. B. Caracteres associados a tolerância ao alumínio tóxico em genótipos de trigos sul brasileiros. Revista Brasileira Agrociência, Pelotas, v. 11, n. 2, p. 149-154, 2005.

CAMARGO, C. E. O.; OLIVEIRA, O. F. Tolerância de cultivares de trigo a diferentes níveis de alumínio em solução nutritiva e no solo. Bragantia, Campinas, v. 40, n. 3, p. 21-31, 1981.

CRESTANI, M.; SILVA, J. A. G.; BERVALD, C. M. P.; MAIA, L. C. da; OLIVEIRA, A. C.; CARVALHO, F. I. F. Related characteristics and multivariate analyses in the evaluation of white oat aluminum tolerance. Communications in Soil Science and Plant Analysis, Athens, v. 42, n. 3, p. 247-262, 2011.

CRESTANI, M.; BARBIERI, R. L.; SILVA, J. A. G. da; CARVALHO, F. I. F.; OLIVEIRA, A. C. Toxidez por alumínio e a seleção de plantas tolerantes com base na expressão fenotípica. Pelotas: Clima Temperado, 2009. 55 p. (Embrapa Clima Temperado. Documentos, 265).

CRUZ, C. D. Programa genes: aplicativo computacional em genética e estatística. Viçosa: UFV, 2001. 648 p.

FAQUIN, V.; VALE, F. R. Toxidez de alumínio e manganês. Informe Agropecuário, Belo Horizonte, v. 15, n. 1, p. 28-38, 1991.

FERREIRA, R. de P.; MOREIRA, A.; RASSINI, J. B. Toxidez de alumínio em culturas anuais. São Carlos, SP: Embrapa Pecuária Sudeste, 2006. 34 p. Embrapa Pecuária Sudeste. (Documentos, 63).

FINATTO, T.; SILVA, J. A. G.; CARVALHO, F. I. F.; OLIVEIRA, A. C.; VALÉRIO, I. P.; REIS, C. E. S.; SILVEIRA, G.; FONSECA, D. A. R. Reação de tolerância de genótipos de aveia branca a concentrações de alumínio em solução nutritiva. Magistra, Cruz das Almas, v. 19, n. 1, p. 7-15, 2007.

FOY, C. D. Physiological effects of hydrogen, aluminum and manganese toxicities in acid soil. In: ADAMS, F. (Ed.). Soil acid and liming. Madison: American Society of Agronomy, 1984. p. 57-97.
FREITAS, F. A.; KOPP, M. M.; SOUSA, R. O.; ZIMMER, P. D.; CARVALHO, F. I. F.; OLIVEIRA, A. C. Absorção de $\mathrm{P}, \mathrm{Mg}$, Ca e $\mathrm{K}$ e tolerância de genótipos de arroz submetidos a estresse por alumínio em sistemas hidropônicos. Ciência Rural, Santa Maria, v. 36, n. 1, p. 72-79, 2006.

HARTWIG, I.; OLIVEIRA, A. C.; CARVALHO, F. I. F.; BERTAN, I.; SILVA, J. A. G.; SCHMIDT, D. A. M.; VALÉRIO, I. P.; MAIA, L. C.; FONSECA, D. N. R.; REIS, C. E. S. Mecanismos associados à tolerância ao alumínio em plantas. Semina Ciências Agrárias, Londrina, v. 28, n. 2, p. 219-228, 2007.

JONES, D. L.; KOCHIAN, L. V.; GILROY, S. Aluminum induces a decrease in cytosolic calcium concentration in BY-tobaco cell cultures. Plant Physiology, Bethesda, v. 116, n. 1, p. 81-89, 1998.

KOCHIAN, L. V. Cellular mechanisms of aluminum toxicity and resistance in plants. Annual Review of Plant Physiology and Plant Molecular Biology, Califórnia, v. 46, n. 1, p. 237-260, 1995.

MACHADO, P. L. O. A. Considerações gerais sobre a toxicidade do alumínio nas plantas. Rio de Janeiro: EMBRAPA CNPMS, (Documentos, 2). 1997. 22 p.

MALKANTHI, D. R. R.; YOKOYAMA, K.; YOSHIDA, T.; MORITSUGU, M.; MATSUSHITA, K. Effects of low $\mathrm{pH}$ and $\mathrm{Al}$ on growth and nutrient uptake of several plants. Soil Science and Plant Nutrition, Tokyo, v. 41, n. 1, p. 161-165, 1995.

NAVA, I. C.; DELATORRE, C. A.; DUARTE, I. T. L.; PACHECO, M. T.; FEDERIZZI, L. C. Inheritance of aluminum tolerance and its effects on grain yield and grain quality in oats (Avena sativa L.). Euphytica, Wageningen, v. 148, n. 3, p. 353-358, 2006.

OLIVEIRA, P. H. Herança genética e mapeamento molecular da tolerância à toxicidade do alumínio em aveia. 2002. Tese (Doutorado em Fitotecnia) - Programa de Pós-graduação em Agronomia. Universidade Federal do Rio Grande do Sul, Porto Alegre.

REIS, C. E. S. dos; SILVA, J. A. G. da; CARVALHO, F. I. F.; OLIVEIRA, A. C.; MARTINS, J. L.; FINATTO, T.; CRESTANI, M. Caracterização de cultivares de aveia quanto à tolerância à toxicidade do alumínio, avaliadas em hidroponia. Revista Brasileira de Agrociência, Pelotas, v. 15, n. 1-4, p. 57-62, 2009.

RYAN, P. R.; DITOMASO, J. M.; KOCHIAN, L. V. Aluminum toxicity in roots: an investigation of spatial sensitivity and the role of the root cap. Journal of Experimental Botany, Oxford, v. 44, n. 2, p. 437-446, 1993. 
SALVADOR, J. O.; MOREIRA, A.; MALAVOLTA, E. Influência do alumínio no crescimento e na acumulação de nutrientes em mudas de goiabeira. Revista Brasileira de Ciência do Solo, Viçosa, MG, v. 24, n. 4, p. 787-796, 2000.

SÁNCHEZ-CHACÓN，C. D.; FEDERIZZI，L. C.; MILACH, S. C. K.; PACHECO, M. T. Variabilidade genética e herança da tolerância à toxicidade do alumínio m aveia. Pesquisa Agropecuária Brasileira, Brasília, v. 35, n. 9, p. 1798-1808, 2000.

SANDERS, D.; BROWNLEE, C.; HARPER, J. F. Communicating with calcium. Plant Cell, Waterbury, v. 11, n. 4, p. 691-706, 1999.

SILVA, J. A. G.; CARVALHO, F. I. F.; COIMBRA, J. L. M.; VIEIRA, E. A.; BENIN, G.; OLIVEIRA, A. C.; FINATTO, T.; BEERTAN, I.; SILVA, G. O.; CORRÊA, M. R. Tolerância ao alumínio em cultivares de aveia branca sob cultivo hidropônico. Bragantia, Campinas, v. 66, n. 4, p. 587-593, 2007.

SIVAGURU, M.; PALIWAL, K. Differential aluminum tolerance in some tropical rice cultivars - II: mechanism of aluminum tolerance. Journal of Plant Nutrition, Philadelphia, v. 16, n. 9, p. 1717-1732, 1993.
SPEHAR, C. R.; SOUZA, L. A. C. Selection for aluminum tolerance in tropical soybeans. Pesquisa Agropecuária Tropical, Goiânia, v. 36, n. 1, p. 1-6, 2006.

STATISTICAL ANALYSIS SYSTEM - SAS. Statistical analysis system - getting started with the SAS learning edition. Cary, NC, SAS Institute Inc., 2002. 86 p.

TAIZ, L.; ZEIGER, E. Fisiologia vegetal. 3. ed. Porto Alegre: Artmed, 2004. 719 p.

TEDESCO, M. J.; GIANELLO, C.; BISSANI, C. A.; BHONEN, H.; VOLKWEISS, S. J. Análise de solo, plantas e outros materiais. 2. ed. Porto Alegre: UFRGS, 1995. $147 \mathrm{p}$.

WAGNER, C. W.; MILACH, S. C. K.; FEDERIZZI, L. C. Genetic inheritance of aluminum tolerance in oat. Crop Breeding and Applied Biotechonology, Viçosa, v. 1, n. 1, p. 22-26, 2001.

WIGHT, C. P.; KIBITE, S.; TINKER, N. A.; MOLNAR, S. J. Identification of molecular markers for aluminum tolerance in diploid oat through comparative mapping and QTL analysis. Theoretical and Applied Genetics, Berlin, v. 112, n. 2, p. 222-231, 2006. 
